\title{
BMJ Open Cross-sectional study evaluating burden and depressive symptoms in family carers of persons with age-related macular degeneration in Australia
}

\author{
Ivan Jin, ${ }^{1}$ Diana Tang (D) ,2 Jessica Gengaroli, ${ }^{3}$ Kathryn Nicholson Perry, ${ }^{3}$ \\ George Burlutsky, ${ }^{2}$ Ashley Craig (D) , ${ }^{4}$ Gerald Liew (D) , ${ }^{1}$ Paul Mitchell, ${ }^{1}$ \\ Bamini Gopinath (iD) ${ }^{2}$
}

To cite: Jin I, Tang D, Gengaroli J, et al. Crosssectional study evaluating burden and depressive symptoms in family carers of persons with age-related macular degeneration in Australia. BMJ Open 2021;11:e048658. doi:10.1136/ bmjopen-2021-048658

- Prepublication history and additional supplemental material for this paper are available online. To view these files, please visit the journal online (http://dx.doi.org/10.1136/ bmjopen-2021-048658).

Received 04 January 2021 Accepted 23 August 2021

Check for updates

(c) Author(s) (or their employer(s)) 2021. Re-use permitted under CC BY-NC. No commercial re-use. See rights and permissions. Published by BMJ.

${ }^{1}$ Centre for Vision Research, University of Sydney, Sydney, New South Wales, Australia ${ }^{2}$ Macquarie University Hearing, Macquarie University, Sydney, New South Wales, Australia ${ }^{3}$ Discipline of Psychological Science, Australian College of Applied Psychology, Sydney, New South Wales, Australia ${ }^{4}$ Northern Clinical School, University of Sydney, St Leonards, New South Wales, Australia

Correspondence to

Bamini Gopinath;

bamini.gopinath@mq.edu.au

\section{ABSTRACT}

Objectives We aimed to analyse the degree of carer burden and depressive symptoms in family carers of persons with age-related macular degeneration (AMD) and explore the factors independently associated with carer burden and depressive symptoms.

Methods Cross-sectional study using self-administered and interviewer-administered surveys, involving 96 family carer-care recipient pairs. Participants were identified from tertiary ophthalmology clinics in Sydney, Australia, as well as the Macular Disease Foundation of Australia database. Logistic regression, Pearson and Spearman correlation analyses were used to investigate associations of explanatory factors (family caregiving experience, carer fatigue, carer quality of life and care-recipient level of dependency) with study outcomes—carer burden and depressive symptoms.

Results Over one in two family carers reported experiencing mild or moderate-severe burden. More than one in five and more than one in three family carers experienced depressive symptoms and substantial fatigue, respectively. High level of care-recipient dependency was associated with greater odds of moderate-severe and mild carer burden, multivariable-adjusted OR 8.42 (95\% $\mathrm{Cl} 1.88$ to 37.60$)$ and $\mathrm{OR} 4.26(95 \% \mathrm{Cl} 1.35$ to 13.43$)$, respectively. High levels of fatigue were associated with threefold greater odds of the carer experiencing depressive symptoms, multivariable-adjusted OR 3.47 (95\% $\mathrm{Cl} 1.00$ to 12.05$)$.

Conclusions A substantial degree of morbidity is observed in family carers during the caregiving experience for patients with AMD. Level of dependency on the family carer and fatigue were independently associated with family carer burden and depressive symptoms.

Trial registration number The trial registration number is ACTRN12616001461482. The results presented in this paper are Pre-results stage.

\section{INTRODUCTION}

Age-related macular degeneration (AMD) is a chronic and progressive disorder of the macula ${ }^{1}$ and is the leading cause of blindness and low vision in Australia, directly affecting more than 1 million persons. ${ }^{23}$ The effects of

\section{Strengths and limitations of this study}

- The study design and method of surveying allowed for the collection of rich and extensive data from patients with age-related macular degeneration and their family carers.

- Several validated scales for the assessment of both carer and patient variables were used, including those for burden, depression, fatigue and visual functioning.

- Study participants were recruited from only one state in Australia.

- Due to the relatively small sample size, the study is likely to be underpowered for detecting modest associations.

vision impairment in AMD are not limited to declining visual function, with several studies showing that AMD affects multiple health domains and leads to significant emotional distress, poorer quality of life and reduced functional independence. ${ }^{4}{ }^{5}$ For many patients, the ongoing nature of a chronic illness like AMD is such that it requires the provision of continuous physical and emotional care beyond the scope of what can be currently provided by hospitals or other institutions. ${ }^{67}$ Family carers of relatives with AMD are often expected to provide a high standard of care despite not receiving formal training and adequate support for this role. ${ }^{89}$ Surveys on the perceptions of family carers of relatives with AMD in their role as informal carers demonstrate experiences of significant psychological distress, with the negative impacts of caring extending to increased financial stress, disruptions to lifestyle and retirement plans and added strain on the relationship between carer and care recipient. ${ }^{510}$ Moreover, previous studies based in the UK have shown that caregivers of patients 
with AMD experience burden levels comparable to those caring for persons with rheumatoid arthritis and multiple sclerosis. ${ }^{11}$ Additionally, comorbidity has been shown to be associated with a higher degree of caregiver burden, as demonstrated in other caregiving settings such as for patients with dementia. ${ }^{12}$ Furthermore, a significant degree of psychological distress has been reported in caregivers of legally blind patients, with one such study reporting more than a third of caregivers experiencing depression. ${ }^{13}$ Previous research conducted by our group on caregiving for AMD has demonstrated that the level of caregiver dependence and the presence of multiple chronic illnesses in the care recipient were independent predictors of psychological distress. ${ }^{14}$

Clearly, the impacts of AMD are far-reaching, with significant influence on family, friends and carers, as well as substantial cost to society. ${ }^{315}$ However, currently, there exists little literature reporting on the level and factors of burden and depressive symptoms experienced by family carers of relatives with AMD. As such, the key aims of this cross-sectional study were to: (1) analyse the degree of carer burden and depressive symptoms in family carers of persons with AMD; and (2) explore the factors that were independently associated with carer burden and depressive symptoms.

\section{METHODS}

\section{Participants}

Participants for this study were recruited as a part of a randomised controlled trial implementing a novel multicomponent intervention targeting the drivers of stress and burden in family carers of patients with AMD. This study analysed a total of 96 patients with AMD and 96 of their family carers who were examined at baseline (preintervention). Recruitment of participants occurred between January 2017 and May 2020 across multiple ophthalmology practices in Sydney, Australia, as well as via the Macular Disease Foundation Australia (MDFA) database of members. The inclusion criteria for eligible family carers participating in this study were: adults aged more than 18 years old; family carer of a relative with AMD; willing to engage in a 10-week cognitive behavioural therapy intervention over a 3-month period and sufficient English fluency to effectively engage in the intervention. All participants in this study gave written informed consent. Information on baseline study participant characteristics were obtained via surveys of family carers and their relatives with AMD, completed onsite during clinic visits or at home either independently or with help from the study coordinator, for example, due to limitations imposed by poor vision.

\section{Patient and public involvement}

It was not appropriate or possible to involve patients or the public in the design, or conduct, or reporting or dissemination plans of our research.

\section{Sociodemographic information and medical history}

All participants (carers and care recipients with AMD) provided sociodemographic information including: age, sex, education level and marital status. They also selfreported any medical conditions such as: heart attacks; angina (without myocardial infarction); any other cardiac conditions; strokes or transient ischaemic attacks; high blood pressure; high cholesterol; diabetes or pre-diabetes; kidney disease; arthritis; hearing loss and visual impairment. This information was used to assess the general health status (GHS) of each participant. Participants who reported three or more health conditions were considered as having substantial comorbidity and received a score of 1 , whereas those with fewer than three health conditions received a score of 0 .

\section{Carer variables}

Family carers were asked to provide details about the patient with AMD that they cared for such as whether they were the sole caregiver of the patient; the type of caregiving duties performed and the hours of care (per day) they provided to the care recipient with AMD. This comprised of 21 questions detailing caregiving duties as they applied to typical activities of daily living and instrumental activities of daily living for the patient with AMD, including exercise and/or sport, cooking and preparing food, cleaning, reading, personal grooming, using public transport, driving and more. Each question was scored reflecting the degree of help given for each activity ( $0=$ no help or little help given, $1=$ moderate amount of help given, $2=$ high amount of help given, $3=$ not applicable). Additional information on family carers was determined by administering several validated instruments and scales as detailed below:

\section{Carer burden}

The Caregiver Burden Scale (CBS) is a 22-item questionnaire originally developed for assessment of perceived family carer burden in caring for patients with dementia. ${ }^{16} 17$ Each question was scored on a 5-point Likert-type scale ( $0=$ never, $1=$ rarely, 2=sometimes, $3=$ quite frequently, 4=always), reflecting the frequency of family carers' feelings when taking care of their family member. The total burden score calculated for each family carer was used to stratify levels of burden into three categories, with higher scores indicating higher levels of burden $(0$ $20=$ no/little burden, 21-40=mild burden, $\geq 41=$ moderate-severe burden $).{ }^{16}$ The CBS is a reliable measure with a Cronbach's alpha of $0.92 .^{18}$

\section{Depressive symptoms}

The short form of the Centre for Epidemiologic Studies Depression (CESD-10) scale is a 10-item questionnaire and was used to screen for symptoms of depression. ${ }^{19}$ Each question gauges the frequency of a family carer experiencing certain symptoms of depression per week and is scored on a 4-point Likert-type scale $(0=$ rarely or none of the time ( $<1$ day), $1=$ some or a little of the time (1-2 days), 
$2=$ occasionally or a moderate amount of the time (3-4 days), $3=$ most or all of the time (5-7 days)). A total CESD-10 score of 10 or more indicates significant presence of depressive symptoms, as reported by previous research evaluating the validity of the CESD-10 scale. ${ }^{19}$ The CESD-10 is a validated and reliable measure with a Cronbach's alpha of $0.80 .^{19} 20$

\section{Fatigue}

The Fatigue Severity Scale (FSS) is a 9-item questionnaire used frequently to assess the degree of impact that fatigue has on an individual's activities and physical functioning. ${ }^{21}$ Participants were asked to respond to statements about how much fatigue impacted their ability to function on a scale of 1 (disagree) to 7 (agree). Previous studies have shown mean (SD) FSS scores for healthy individuals to be $2.3(0.7) .{ }^{21}$ Mean FSS scores of 4 or more were categorised as having problematic fatigue. The FSS is a validated and reliable measure with a Cronbach's alpha of $0.88 .{ }^{21}$

\section{Self-efficacy}

The General Self-Efficacy (GSE) scale is a 10-item questionnaire shown to be effective at measuring one's beliefs of overall ability to succeed in specific situations. ${ }^{22}$ The degree of how much a family carer agreed with each statement was measured using a 4-point Likert-type scale ( $0=$ not true, $1=h a r d l y$ true, $2=$ moderately true, $3=$ exactly true) . Higher total GSE scores indicate higher self-efficacy.

\section{Dependency}

Carers were asked to quantify the level of dependence their family member with AMD had on them since their diagnosis using a 5-point Likert-type scale ( $1=$ not at all dependent, 2=somewhat dependent, 3=moderately dependent, $4=v e r y$ dependent, $5=$ extremely dependent). Scores 3 or more were interpreted as an indication of high dependency on the family carer (1-2=low dependency, 3-5=high dependency).

\section{Quality of life}

Carer's rated their general quality of life (GQL) on a linear scale from 0 (poor quality of life) to 10 (excellent quality of life).

\section{Care recipients with AMD}

The National Eye Institute Visual Function Questionnaire-25 (NEI VFQ-25) was completed by care recipients, and is a reliable and validated tool used to measure status of vision-related health impairment most relevant to patients with chronic eye conditions. ${ }^{23}$ Questions in the NEI VFQ-25 were used to determine the extent of how visual disability and symptoms negatively impacts the patient's ability to function, well-being and efficacy in achieving vision-related tasks. The NEI VFQ-25 is comprised of 12 subscales, assessing general vision, near and distance vision, vision-related difficulty with activities, vision-related driving problems, eye pain, colour vision, dependency, impact on social functioning, mental health and general health. ${ }^{23}$ Scores recorded in the original response category for each question were recoded to a scale between 0 and 100 in accordance with the NEI VFQ-25 scoring algorithm, with higher scores indicating greater vision-related well-being.

\section{Statistical analysis}

SAS statistical software (SAS Institute, NC, V.9.4) was used for the statistical analysis, including t-tests, $\chi^{2}$ tests, F-test and logistical regression. We analysed caregiver burden as a categorical variable based on the previous literature by Zarit $e a^{16}$ and the generalised logits model was used for carer burden, given that it is a three-level categorical variable. ${ }^{24} \mathrm{~A}$ binary logistic regression was used for the study outcome of depressive symptoms as it is a two-level variable. For all models, a stepwise selection method was used.

Predictor variables assessed for both these study outcomes were: carer age, carer sex, carer GQL, carer GHS, fatigue severity, GSE, level of dependency on the carer, patient age, patient sex, patient GHS and patient NEI VFQ-25 scores. The CORR procedure was used to compute the Pearson correlations and Spearman rankorder correlations between the presence of depressive symptoms (CESD-10 score) and the following variables: patient age and sex, and carer variables (age, sex, GQL scores, FSS scores, carer and patient GHS, GSE, level of dependency on the carer and NEI VFQ-25 scores). The significance level was $<0.05$. Checks for multicollinearity did not return any confirmation of multicollinearity occurring.

\section{RESULTS}

\section{AMD caregiving experience and health-related variables}

The majority of family carers $(91 \%)$ were aged 50 years and over, with family carers aged 65 years or older making up 54\% of the sample. The proportion of females was $78 \%$ and $66 \%$ among family carers and care recipients with AMD, respectively. Of the 96 family carers in this study, $75 \%$ were the sole carer of the patients with AMD, with $43 \%$ reporting that the family member they cared for was highly dependent on them. Family carers played a considerable role in helping their relatives access medical care, with $91 \%$ accompanying their relatives to their ophthalmology appointments where the majority of relatives with AMD (79\%) were receiving anti-VEGF injections. In terms of how often help was provided to relatives with AMD, $61 \%$ of family carers reported providing help for 7 days a week on average, with $45 \%$ reporting either spending $>8$ hours per day with them or living together with the care recipient. The main caregiving duties where carers provided moderate to high amounts of help included cooking (57\%), cleaning $(60 \%)$ and help with leaving the house $(70 \%)$.

Substantial amounts of fatigue were experienced by $36 \%$ of family carers as indicated by scores of 4 or higher on the FSS, and a considerable degree of general health comorbidities was reported by $29 \%$ of family carers. The mean quality of life and GSE scores among the family 
Table 1 Study characteristics of family carers stratified by degree of burden experienced as measured by carer sex, age, general health status, FSS scores, CESD-10 scores, GSE scores, GQL scores and care-recipient sex, age, general health status and NEI VFQ-25 scores $(n=96)$

\begin{tabular}{|c|c|c|c|c|}
\hline \multirow[b]{2}{*}{ Population characteristics } & \multicolumn{4}{|l|}{ Degree of burden } \\
\hline & $\begin{array}{l}\text { No/little burden } \\
(n=41)\end{array}$ & $\begin{array}{l}\text { Mild burden } \\
(\mathrm{n}=33)\end{array}$ & $\begin{array}{l}\text { Moderate-severe burden } \\
(\mathrm{n}=21)\end{array}$ & $P$ value \\
\hline \multicolumn{5}{|l|}{ Carer variables } \\
\hline Female sex, $n(\%)$ & $28(68.3)$ & $28(84.9)$ & $18(85.7)$ & 0.15 \\
\hline Age, years, mean $(S D)$ & $66.5(15.6)$ & $63.1(13.1)$ & $59.1(10.4)$ & 0.14 \\
\hline $\begin{array}{l}\text { General health status } \\
\text { Substantial comorbidity, } n(\%)\end{array}$ & $15(36.6)$ & $11(33.3)$ & $2(9.5)$ & 0.07 \\
\hline $\begin{array}{l}\text { Fatigue severity scale score } \\
\text { Problematic fatigue }(\geq 4), n(\%)\end{array}$ & $11(26.8)$ & $11(33.3)$ & $12(57.1)$ & 0.06 \\
\hline $\begin{array}{l}\text { CESD-10 score } \\
\text { Presence of depressive symptoms ( } \geq 10), n(\%)\end{array}$ & $6(14.6)$ & $7(21.2)$ & $10(47.6)$ & 0.01 \\
\hline Total general self-efficacy scores, mean (SD) & $33.0(5.4)$ & $32.7(4.1)$ & $31.0(4.5)$ & 0.32 \\
\hline Total general quality of life scores, mean (SD) & $7.6(1.7)$ & $7.5(1.8)$ & $6.6(2.0)$ & 0.09 \\
\hline \multicolumn{5}{|l|}{ Patient variables } \\
\hline Female sex, $n(\%)$ & $25(61.0)$ & $20(60.6)$ & $17(81.0)$ & 0.23 \\
\hline Age, years, mean $(S D)$ & $81.0(10.1)$ & $84.5(7.2)$ & $85.4(11.1)$ & 0.15 \\
\hline $\begin{array}{l}\text { General health status } \\
\text { Substantial comorbidity, } n(\%)\end{array}$ & $19(46.3)$ & $15(45.5)$ & $14(66.7)$ & 0.25 \\
\hline Total NEI VFQ-25 scores, mean (SD) & $62.7(21.0)$ & $53.6(53.6)$ & $30.6(20.9)$ & $<0.0001$ \\
\hline
\end{tabular}

Unadjusted $\mathrm{P}$ values from test of heterogeneity across the three burden categories.

CESD-10, Centre for Epidemiologic Studies Depression-10; FSS, Fatigue Severity Scale; GQL, General Quality of Life; GSE, Generalised SelfEfficacy; NEI VFQ-25, National Eye Institute Visual Functioning Questionnaire-25.

carers in this study were: 7.3 (SD 2.0) and 32.5 (SD 4.9), respectively.

\section{Burden analysis}

More than half of family carers reported experiencing mild $(35 \%)$ and moderate-severe $(22 \%)$ burden due to their caregiving experience (table 1). Family carers of highly dependent relatives with AMD were more likely to experience moderate-severe and mild burden after multivariable adjustment: OR 8.42 (95\% CI 1.88 to 37.60) and 4.26 (95\% CI 1.35 to 13.43), respectively (table 2 ). Marginally significant associations were observed between the age and visual functioning of the care recipient with AMD and the level of burden experienced by family carers (table 2). Younger carer age, older care recipient age, higher fatigue severity, high level of dependency on the carer and lower NEI VFQ-25 scores were significantly correlated with more carer burden (online supplemental table 1). No statistically significant correlations were observed between carer burden scores and carer sex, patient sex, carer GQL scores (quality of life), carer and patient GHS scores (GHS and carer GSE scores (data not shown).

\section{Depressive symptoms}

Over one in five family carers (24\%) demonstrated a significant presence of depressive symptoms as determined by the CESD-10 scale (ie, total score 10 or more). Table 3 shows that family carers with higher levels of fatigue were more likely to experience depressive symptoms: OR 3.47

Table 2 Association between selected family carer and care recipient with AMD variables with level of burden among family carers, presented as adjusted OR and $95 \% \mathrm{Cl}$

\begin{tabular}{lll}
\hline & \multicolumn{2}{l}{ Level of burden, OR $(\mathbf{9 5 \%} \mathbf{C l})^{\star}$} \\
\cline { 2 - 3 } Factors & Mild & Moderate-severe \\
\hline Care-recipient age (each 1-unit increase) & $1.03(0.97$ to 1.09$)$ & $0.99(0.92$ to 1.07$)$ \\
NEI VFQ-25 score (each 1-unit increase) & $1.00(0.98$ to 1.02$)$ & $0.96(0.93$ to 0.99$)$ \\
\hline High level of dependency on carer & $4.26(1.35$ to 13.43$)$ & $8.42(1.88$ to 37.60$)$ \\
\hline
\end{tabular}

*Logistic regression model (Generalised Logit Model) used the burden group 0-20 (no/little burden) as the reference category.

AMD, age-related macular degeneration; NEI VFQ-25, National Eye Institute Visual Functioning Questionnaire-25. 
Table 3 Associations between selected variables and presence of depressive symptoms among family carers and care recipients with AMD, presented as adjusted OR and $95 \% \mathrm{Cl}$

Presence of

depressive symptoms, OR

Factor $(95 \% \mathrm{Cl})$

\begin{tabular}{ll}
\hline Family carer & 0.98 (0.93 to 1.04) \\
$\begin{array}{l}\text { Age (each 1-unit increase) } \\
\text { Female sex }\end{array}$ & 0.58 (0.13 to 2.60) \\
$\begin{array}{l}\text { General quality of life (each 1-unit } \\
\text { increase) }\end{array}$ & 0.60 (0.41 to 0.88) \\
$\begin{array}{l}\text { Fatigue severity scale score (each } \\
\text { 1-unit increase) }\end{array}$ & 3.47 (1.00 to 12.05) \\
$\begin{array}{l}\text { General self-efficacy (each 1-unit } \\
\text { increase) }\end{array}$ & 0.97 (0.86 to 1.10) \\
$\begin{array}{l}\text { Care recipients with AMD } \\
\begin{array}{l}\text { Age (each 1-unit increase) } \\
\text { Female sex }\end{array}\end{array}$ & 0.98 (0.90 to 1.05) \\
$\begin{array}{l}\text { General health status (each 1-unit } \\
\text { increase) }\end{array}$ & 1.29 (0.27 to 6.25) \\
$\begin{array}{l}\text { NEI VFQ-25 (each 1-unit increase) } \\
\text { (0.53 to 6.40) }\end{array}$ & 0.98 (0.95 to 1.01) \\
\hline
\end{tabular}

AMD, age-related macular degeneration; NEI VFQ-25, National Eye Institute Visual Functioning Questionnaire-25.

(95\% CI 1.00 to 12.05 ). Conversely, each unit increase in family carer GQL scores was associated with $40 \%$ reduced odds of experiencing depressive symptoms: OR 0.60 (95\% CI 0.41 to 0.88 ). Statistically significant negative correlations between carer CESD-10 scores and carer GQL and GSE scores and care-recipient NEI VFQ-25 scores were observed, and a significant positive correlation was shown between CESD-10 and carer FSS (online supplemental table 2). No statistically significant correlations were observed between CESD-10 and carer age and sex, patient age and sex, carer and patient GHS scores and level of dependency on the carer (data not shown).

\section{DISCUSSION}

This novel study shows that family carers experience substantial levels of burden, depressive symptoms and fatigue when caring for relatives with AMD. The findings from this study are consistent with other studies that demonstrated poorer well-being of family carers of relatives with AMD. ${ }^{11}$ Older carers of relatives with chronic disease are themselves biologically vulnerable to disease and are at substantial risk of developing health problems themselves, with studies showing family carers who experienced strain during their experience of providing care to be at greater risk of increased psychiatric morbidity. ${ }^{25} 26$ This is also reflected by the finding that nearly a third of family carers in this study were providing care for their relatives with AMD while experiencing significant medical morbidity themselves including, cardiovascular disease, cerebrovascular disease, kidney disease, arthritis and diabetes. The continuous nature and stresses of providing care, together with burdensome physical and emotional demands on a population already at risk of declining health outcomes is a significant area of concern, both due to declining health associated with the strain of providing care, and also because any compromise of carer health may in effect lead to inadequate provision of optimal care to the relative with AMD. ${ }^{1127}$

More than half of family carers of relatives with AMD reported experiencing mild or moderate-severe burden. In comparison, a cross-sectional study on caregiver burden for blind persons in India demonstrated a greater proportion of caregivers scoring $\geq 41$ on the CBS (91.8\%), that is, demonstrating substantial amounts of moderate to severe burden. ${ }^{28}$ However, it is perhaps unsurprising that higher levels of burden were reported, given the more severe visual impairment of the population studied. Other areas of interest that should be considered for future research are differences in setting, availability of community support, socioeconomic status and cultural attitudes that may also influence perceived caregiver burden. ${ }^{28}$

When compared with burden experienced by caregivers of patients with idiopathic Parkinson's disease, a greater proportion of family carers of patients with AMD experience moderate-severe burden $(22 \%)$ than carers supporting family with early $(10 \%)$ and late $(\sim 12 \%)$ stages of idiopathic Parkinson's disease. ${ }^{29}$ In contrast, studies on caregivers for patients with stroke report higher levels of moderate-severe burden $(\sim 68 \%) .{ }^{30}$ Interestingly, a recent study on family and unpaid carers of older persons revealed that carers were at greater risk of experiencing burden when caring for patients with dementia with or without substantial disability, but not for those patients with substantial disability in the absence of dementia. ${ }^{31}$ While patient functional impairment has been shown to be associated with higher levels of caregiver burden, this suggests that the additional challenges of caring for patients with dementia may be an issue that is not as relevant for the provision of care to patients with AMD. ${ }^{32}$

The level of dependency that patients with AMD had on their family carers was independently associated with carer burden. This is in agreement with prior research by our group showing that family carers of patients with AMD that had high levels of dependency on them experience negative impacts such as high levels of emotional distress, as well as disruptions to their lifestyle and retirement plans. ${ }^{5}$ Moreover, a systematic review of depression and burden among caregivers of patients with visual impairment found that greater hours of supervision required and greater limitations in the patients' ability to carry out their activities of daily living, to be among the factors commonly associated with caregiver burden, ${ }^{33}$ a finding reflected in our study. It is likely that a high level of dependency on family carers may negatively impact the relationship between the carer and care recipient. Higher levels of dependency by the care recipient could 
be linked to loss of independence in the family carer due to a lack of time for one's own needs and leisure activities and this in turn could lead to feelings of burden. ${ }^{10}$ Moreover, carers have previously reported feelings of guilt from inability to provide the constant and necessary care, with some carers experiencing feelings of being manipulated by the care recipient. ${ }^{510}$ These feelings of burden due to the AMD caregiving experience can have profound implications on family carer health and well-being. Previous research conducted on the caregiving experience for elderly patients with chronic illnesses has demonstrated negative impacts on the carer's physical and psychological well-being, such as experiencing increased psychological distress, reduced engagement with preventative health behaviours and disruptions to employment and increased financial stress ${ }^{5} 1034$

In contrast, around 1 in 10 family carers of relatives with AMD in this study experienced positive impacts of providing care, including feeling happier and more content with their lives, as well as feeling more optimistic and determined. It is possible that these differences of the caregiving experience among family carers may be related to pre-existing strong familial ties and/or relationships, or otherwise relationships that have strengthened since the need for family caregiving. Indeed, research into the role of partner relationship quality and reciprocity (ie, a mutual sense of fair exchange) has demonstrated benefits on caregiver well-being. ${ }^{356}$ Another study examining the role of reciprocity in providing care for persons with dementia, chronic physical disability/illness, frailty from ageing and intellectual disability showed an inverse relationship between reciprocity and self-esteem to caregiver burden. ${ }^{36}$ These high-quality relationships may in fact provide the resources and means to alleviate the stress and burden that would otherwise be present during the provision of care. ${ }^{36}$ As such, understanding the factors that determine relationship strength and how they can be targeted may be a potential area to address when aiming to improve equity in the family carer-care-recipient dynamic.

Over one in five family carers of relatives with AMD demonstrated a significant presence of depressive symptoms in our study, and this is substantially higher that the global prevalence rates of $\sim 6 \% .{ }^{37}$ Higher rates of depressive symptoms $(\sim 35 \%)$ have also been demonstrated in previous studies of family carers of patients with vision loss, along with significant associations between depressive symptoms and younger carer age and poorer patient visual acuity. ${ }^{38}$ High rates $(40 \%)$ of caregivers reporting depressive symptoms were found in a study on family carers of patients with Alzheimer's disease ${ }^{39}$ Higher levels of fatigue were shown to be predictive of family carers experiencing depressive symptoms in our study. This is perhaps unsurprising, given that fatigue and its symptoms are well-known symptoms/predictors of major depressive disorder in the general population. ${ }^{40}$ Studies on the emotional well-being of carers of patients with AMD have previously reported increased rates of emotional distress, feelings of frustration, isolation and sadness. ${ }^{5} 1334$

Furthermore, poorer family carer quality of life was significantly associated with depressive symptoms. This association between quality of life and depressive symptoms is consistent with other cross-sectional and longitudinal studies involving older adults. ${ }^{41}$ Poor quality of life limits one's ability to carry out their social and occupational activities. ${ }^{42}{ }^{43}$ Previous studies on caregiver quality of life have suggest that financial burden, lack of family/ social support, distress and unmet needs are among the factors purportedly increasing the risk of depression and poor mental health outcomes. ${ }^{44-46}$

Strengths of this study include the collection of rich and extensive outcome and covariate data from patients with AMD and their family carers, as well as the use of several validated scales for the assessment of carer and patient variables such as burden, depression, fatigue and visual functioning. However, findings of this study should be interpreted with caution. Due to the relatively small sample size, it is likely that the study was underpowered to detect modest associations, as well as limiting the generalisability of the results. Similarly, in the analyses, small sample sizes accounted for large CIs, providing less precise estimates of effect. The use of other tools such as the Barthel index for the measurement of care-recipient dependency may have been potentially useful in providing a more accurate quantification of dependency. However, while this is a reliable measure of dependency, it is time consuming, given that direct observation of the person performing specific tasks is required. Also, we cannot discount residual confounding from factors that were not measured in our study such as the quality/ strength of the carer-care-recipient relationship and other psychosocial measures such as spirituality and carer resilience. Moreover, the cross-sectional study design implemented was useful for investigating the relationships between various factors and health outcomes. However, this design limits our ability to draw conclusions about causality. Longitudinal and experimental analyses would allow for a better understanding of causality and the temporal interactions and relationships between variables in this study. As such, future studies of these types utilising larger population sets would be useful to affirm the findings of this study.

\section{CONCLUSION}

A substantial proportion of family carers of relatives with AMD experience significant burden and depressive symptoms. Family carers played a considerable role in the care of relatives with AMD, including aiding with access to medical care and assistance with care-recipient's ADLs. Levels of dependency and fatigue, as well as lower quality of life, were independently associated with higher levels of burden and/or greater odds of depressive symptoms in family carers. Further research is required to affirm these conclusions regarding these predictors of burden 
and depressive symptoms in family carers of relatives with AMD.

Acknowledgements The authors thank all individuals for their time and participation in the study.

Contributors All authors—IJ, DT, GB, JG, KNP, AC, GL, PM and BG—provided inputs in study design. IJ, DT, JG, GB, PM and BG were involved in data collection and data analysis. IJ, JG and BG were responsible for publication writing. All authors reviewed and approved the final version of this manuscript.

Funding This work was supported by the Australian National Health and Medical Research Council under a Partnership Project Grant (APP1115729); and the Macular Disease Foundation Australia.

Competing interests None declared.

Patient consent for publication Not required.

Ethics approval Ethics approval was obtained from The University of Sydney Human Research Ethics Committee (ID\#-2016/793).

Provenance and peer review Not commissioned; externally peer reviewed.

Data availability statement Data are available upon reasonable request. Deidentified participant data will be available upon request made to the corresponding author.

Supplemental material This content has been supplied by the author(s). It has not been vetted by BMJ Publishing Group Limited (BMJ) and may not have been peer-reviewed. Any opinions or recommendations discussed are solely those of the author(s) and are not endorsed by BMJ. BMJ disclaims all liability and responsibility arising from any reliance placed on the content. Where the content includes any translated material, BMJ does not warrant the accuracy and reliability of the translations (including but not limited to local regulations, clinical guidelines, terminology, drug names and drug dosages), and is not responsible for any error and/or omissions arising from translation and adaptation or otherwise.

Open access This is an open access article distributed in accordance with the Creative Commons Attribution Non Commercial (CC BY-NC 4.0) license, which permits others to distribute, remix, adapt, build upon this work non-commercially, and license their derivative works on different terms, provided the original work is properly cited, appropriate credit is given, any changes made indicated, and the use is non-commercial. See: http://creativecommons.org/licenses/by-nc/4.0/.

\section{ORCID iDs}

Diana Tang http://orcid.org/0000-0003-2007-9054

Ashley Craig http://orcid.org/0000-0001-7647-7604

Gerald Liew http://orcid.org/0000-0001-7422-0012

Bamini Gopinath http://orcid.org/0000-0003-3573-359X

\section{REFERENCES}

1 Mitchell P, Liew G, Gopinath B, et al. Age-related macular degeneration. Lancet 2018;392:1147-59.

2 Wang JJ, Rochtchina E, Lee AJ, et al. Ten-year incidence and progression of age-related maculopathy: the blue Mountains eye study. Ophthalmology 2007;114:92-8.

3 Economics DA, Mitchell P. Eyes on the future: a clear outlook on age-related macular degeneration. Macular Degeneration Foundation Australia, 2011: 144.

4 Ranmuthugala G, Nepal B, Brown L, et al. Impact of home based long term care on informal carers. Aust Fam Physician 2009;38:618-20.

5 Gopinath B, Liew G, Burlutsky G, et al. Age-related macular degeneration and 5-year incidence of impaired activities of daily living. Maturitas 2014;77:263-6.

6 Berman K, Brodaty H. Psychosocial effects of age-related macular degeneration. Int Psychogeriatr 2006;18:415-28.

7 Gehrs KM, Anderson DH, Johnson LV, et al. Age-related macular degeneration--emerging pathogenetic and therapeutic concepts. Ann Med 2006;38:450-71.

8 Goldberg A, Rickler KS. The role of family caregivers for people with chronic illness. Med Health R I 2011;94:41-2.

9 Bialon LN, Coke S. A study on caregiver burden: stressors, challenges, and possible solutions. Am J Hosp Palliat Care 2012;29:210-8.

10 Vukicevic M, Heraghty J, Cummins R, et al. Caregiver perceptions about the impact of caring for patients with wet age-related macular degeneration. Eye 2016;30:413-21.
11 Gohil R, Crosby-Nwaobi R, Forbes A, et al. Caregiver burden in patients receiving ranibizumab therapy for neovascular age related macular degeneration. PLoS One 2015;10:e0129361.

12 Lindt N, van Berkel J, Mulder BC. Determinants of overburdening among informal carers: a systematic review. BMC Geriatr 2020;20:304.

13 Braich PS, Lal V, Hollands S, et al. Burden and depression in the caregivers of blind patients in India. Ophthalmology 2012;119:221-6.

14 Gopinath B, Kifley A, Cummins R, et al. Predictors of psychological distress in caregivers of older persons with wet age-related macular degeneration. Aging Ment Health 2015;19:239-46.

15 Wong WL, Su X, Li X, et al. Global prevalence of age-related macular degeneration and disease burden projection for 2020 and 2040: a systematic review and meta-analysis. Lancet Glob Health 2014;2:e106-16.

16 Zarit SH, Reever KE, Bach-Peterson J. Relatives of the impaired elderly: correlates of feelings of burden. Gerontologist 1980;20:649-55.

17 Bédard M, Molloy DW, Squire L, et al. The Zarit burden interview: a new short version and screening version. Gerontologist 2001;41:652-7.

18 Hébert R, Bravo G, Préville M. Reliability, validity and reference values of the Zarit burden interview for assessing informal caregivers of community-dwelling older persons with dementia. Canadian Journal on Aging / La Revue canadienne du vieillissement 2000;19:494-507.

19 Andresen EM, Malmgren JA, Carter WB, et al. Screening for depression in well older adults: evaluation of a short form of the CES-D (center for epidemiologic studies depression scale). Am J Prev Med 1994;10:77-84.

20 Irwin M, Artin KH, Oxman MN. Screening for depression in the older adult: criterion validity of the 10-item center for epidemiological studies depression scale (CES-D). Arch Intern Med 1999;159:1701-4.

21 Krupp LB, LaRocca NG, Muir-Nash J, et al. The fatigue severity scale. Application to patients with multiple sclerosis and systemic lupus erythematosus. Arch Neurol 1989;46:1121-3.

22 Schwarzer R, Jerusalem M. Measures in health psychology: A user's portfolio. Causal and control beliefs. In: Weinman J, Wright S, Johnston M, eds. Generalized self-efficacy scale. Windsor, England: NFER-Nelson, 1995: 35-7.

23 Mangione CM, Lee PP, Gutierrez PR, et al. Development of the 25 -item National eye Institute visual function questionnaire. Arch Ophthalmol 2001;119:1050-8.

24 Elkin E. Beyong binary outcomes: proC logistic to model ordinal and nominal dependent variables. San Francisco, CA, USA: ICON Late Phase \& Outcomes Research, 2012.

25 Schulz R, Beach SR. Caregiving as a risk factor for mortality: the caregiver health effects study. JAMA 1999;282:2215-9.

26 Vitaliano PP, Schulz R, Kiecolt-Glaser J, et al. Research on physiological and physical concomitants of caregiving: where do we go from here? Ann Behav Med 1997;19:117-23.

27 Cain CJ, Wicks MN. Caregiver attributes as correlates of burden in family caregivers coping with chronic obstructive pulmonary disease. J Fam Nurs 2000;6:46-68.

28 Khare S, Rohatgi J, Bhatia MS, et al. Burden and depression in primary caregivers of persons with visual impairment. Indian $J$ Ophthalmol 2016;64:572-7.

29 Genç F, Yuksel B, Tokuc FEU. Caregiver burden and quality of life in early and late stages of idiopathic Parkinson's disease. Psychiatry Investig 2019;16:285-91.

30 Hu P, Yang Q, Kong L, et al. Relationship between the anxiety/ depression and care burden of the major caregiver of stroke patients. Medicine 2018;97:e12638.

31 Riffin C, Van Ness PH, Wolff JL, et al. Multifactorial examination of caregiver burden in a national sample of family and unpaid caregivers. J Am Geriatr Soc 2019;67:277-83.

32 Liu S, Li C, Shi Z, et al. Caregiver burden and prevalence of depression, anxiety and sleep disturbances in Alzheimer's disease caregivers in China. J Clin Nurs 2017;26:1291-300.

33 Kuriakose RK, Khan Z, Almeida DRP, et al. Depression and burden among the caregivers of visually impaired patients: a systematic review. Int Ophthalmol 2017;37:767-77.

34 Pinquart M, Sörensen S. Differences between caregivers and noncaregivers in psychological health and physical health: a metaanalysis. Psychol Aging 2003;18:250-67.

35 Hirschfeld M. Home care versus institutionalization: family caregiving and senile brain disease. Int J Nurs Stud 2003;40:463-9.

36 Reid CE, Moss S, Hyman G. Caregiver reciprocity: the effect of reciprocity, carer self-esteem and motivation on the experience of caregiver burden. Aust J Psychol 2005;57:186-96.

37 Malhi GS, Mann JJ. Depression. Lancet 2018;392:2299-312. 
38 Bambara JK, Owsley C, Wadley V, et al. Family caregiver social problem-solving abilities and adjustment to caring for a relative with vision loss. Invest Ophthalmol Vis Sci 2009;50:1585-92.

39 Mausbach BT, Chattillion EA, Roepke SK, et al. A comparison of psychosocial outcomes in elderly Alzheimer caregivers and noncaregivers. Am J Geriatr Psychiatry 2013;21:5-13.

40 Corfield EC, Martin NG, Nyholt DR. Co-occurrence and symptomatology of fatigue and depression. Compr Psychiatry 2016;71:1-10.

41 Sivertsen H, Bjørkløf GH, Engedal K, et al. Depression and quality of life in older persons: a review. Dement Geriatr Cogn Disord 2015;40:311-39.

42 Shumye S, Belayneh Z, Mengistu N. Health related quality of life and its correlates among people with depression attending outpatient department in Ethiopia: a cross sectional study. Health Qual Life Outcomes 2019;17:1-9.

43 Evans S, Banerjee S, Leese M, et al. The impact of mental illness on quality of life: a comparison of severe mental illness, common mental disorder and healthy population samples. Qual Life Res 2007;16:17-29.

44 Song JI, Shin DW, Choi JY, et al. Quality of life and mental health in family caregivers of patients with terminal cancer. Support Care Cancer 2011;19:1519-26.

45 Butow PN, Price MA, Bell ML, et al. Caring for women with ovarian cancer in the last year of life: a longitudinal study of caregiver quality of life, distress and unmet needs. Gynecol Oncol 2014;132:690-7.

46 Price MA, Butow PN, Costa DSJ, et al. Prevalence and predictors of anxiety and depression in women with invasive ovarian cancer and their caregivers. Med J Aust 2010;193:S52-7. 